\title{
From the Managing Editor
}

\section{Dear Colleagues:}

It gives me great pleasure to introduce volume 36, issue 2 of the American Review of Politics, our first issue featuring our new and vastly improved layout and style. The progress we have made over the past few issues has been marked: the volume of submissions we now receive has been higher than at any time since $A R P$ came to the University of Oklahoma in 2014, while $A R P$ 's readership continues to steadily grow. One point of pride has remained constant: the high quality of our submissions. As ever, ARP continues to publish some of the most innovative and thoughtful work in the discipline. This is entirely down to the hard work of our authors and reviewers, all of whom have our profound thanks.

I also wish to express my thanks to ARP's partners at the University of Oklahoma. Considerable institutional and financial support from the College of Arts and Sciences and the Department of Political Science have made ARP's revival and continued publication possible. ARP's publishing partners at the University of Oklahoma Libraries have made our entire print run freely available online and continue to operate and support $A R P$ 's electronic publishing platform. Profound thanks especially to David Corbly, Jen Waller, Karen Rupp-Serrano, Interim Dean Carl Grant, and Dean Emeritus Rick Luce.

As $A R P$ confidently looks towards the future, please continue to promote it amongst your colleagues and graduate students. Together, we will continue to demonstrate the enormous potential of open-access publishing as an outlet for high quality scholarship in the social sciences.

Collegially,

Anna E. Kierig George Mason University Managing Editor 